\title{
SYNTHESIS, CHARACTERIZATION AND ANTIBACTERIAL ACTIVITY OF A NEW DERIVATIVE OF LEVOFLOXACIN
}

\author{
AURA RUSU ${ }^{a}$, SILVIA IMRE ${ }^{b}$, ANCA DELIA MARE ${ }^{c}$, IOANA-ANDREEA LUNGU ${ }^{d}$, \\ GEORGIANA-ANDREEA PASCU ${ }^{e *}$ AND VALENTINA UIVAROSI ${ }^{f}$
}

\author{
${ }^{a}$ Pharmaceutical and Therapeutical Chemistry Department, Faculty of Pharmacy, George Emil Palade University of Medicine, Pharmacy, Science and Technology \\ of Târgu Mureş, Târgu Mureş, Romania. \\ ${ }^{b}$ Analytical Chemistry and Drug Analysis Department, Faculty of Pharmacy, George Emil Palade University of Medicine, Pharmacy, Science and Technology of \\ Târgu Mureş, Târgu Mureş, Romania. \\ ${ }^{c}$ Microbiology, Virusology and Parasitology Department, Faculty of Medicine, George Emil Palade University of Medicine, Pharmacy, Science and Technology of \\ Târgu Mureş, Târgu Mureş, Romania. \\ ${ }^{d}$ Doctoral School of Medicine and Pharmacy, George Emil Palade University of Medicine, Pharmacy, Science and Technology of Târgu Mureş, Târgu Mureș, \\ Romania. \\ ${ }^{e}$ Georgiana-Andreea Pascu, Regulatory Affairs Specialist, Gedeon Richter Romania, Târgu Mureş, Romania. \\ ${ }^{f}$ General and Inorganic Chemistry Department, Faculty of Pharmacy, Carol Davila University of Medicine and Pharmacy, Bucharest, Romania.
}

\begin{abstract}
A new levofloxacin derivative using silver triflate with antibacterial activity was synthesized and characterized. The new compound has been physicochemically characterized through elemental analysis, spectroscopic and thermal methods. All correlated experimental data suggested that the levofloxacin triflate was obtained. The antibacterial activity of the new compound was tested against six Gram-positive and Gram-negative bacteria. In vitro, the new compound had similar activity to levofloxacin against Staphylococcus aureus, Escherichia coli and Klebsiella pneumoniae and very closed to the minimum inhibitory concentration values of levofloxacin against Staphylococcus aureus MRSA, Enterococcus faecalis, and Pseudomonas aeruginosa.
\end{abstract}

Keywords: levofloxacin, triflate, silver triflate, antibacterial, antibiotic resistance.

\section{INTRODUCTION}

Increasing antibiotic resistance of bacteria has become a real threat to humanity. Worldwide many organizations and governments fight and try to align their action plans to combat this dangerous phenomenon [1]. Nowadays, only a few new antibiotics have been discovered and introduced into therapy. Unfortunately, no new class of antibiotics has been found for decades [2]. Levofloxacin (LVF) is a third-generation fluoroquinolone, the $S$ stereoisomer of the racemic ofloxacin (Figure 1) [3].

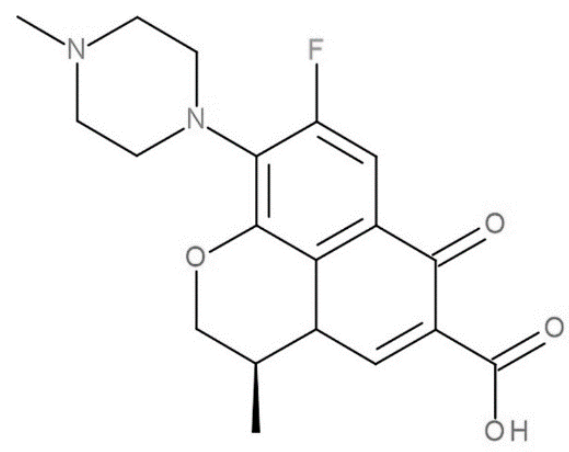

Figure 1. The chemical structure of LVF: (S)-9-fluoro-2,3-dihydro-3-methyl10-(4-methylpiperazin-1-yl)-7-oxo-7H-pyrido[1,2,3-de]-1,4-benzoxazine-6carboxylic acid.

LVF interfere with bacterial DNA synthesis by inhibiting DNA gyrase and topoisomerase IV, the two target enzymes. LVF has a broad spectrum being active on Gram-positive, Gram-negative bacteria, and atypical bacteria. LVF has been used successfully to treat a large number of severe infectious diseases $[4$, 5]. Researchers strive to obtain new antibacterial compounds through the design of new fluoroquinolone derivatives to combat increasing bacterial resistance [68]. Previously, synthesized silver complexes with LVF still had the antibacterial activity similar to that of LVF [9].

The primary purpose of the present work is to obtain a new derivative of LVF with increased antibacterial activity and therapeutically valuable new compound taking into consideration silver trifluoromethanesulfonate (silver triflate) (STF) as a chemical derivative partner.

\section{EXPERIMENTAL}

\section{Materials, methods and instrumentation}

LVF and STF were purchased from Sigma-Aldrich. All other chemicals and organic solvents used were of analytical reagent grade.

A Perkin Elmer PE 2400 (USA) analyzer was used for CHN elemental analyses. After the destruction of the obtained compound in a Berghof microwave digestion system, the silver content was checked by flame atomic absorption spectrometry (FAAS) analysis using a Shimadzu AA 6300 spectrometer. The FT-IR spectra were recorded and processed with an FT-IR Thermo Nicolet (USA) spectrometer and Omnic V.6 software. All samples were prepared as $\mathrm{KBr}$ pellets in the range of $400-4000 \mathrm{~cm}^{-1}$. An Agilent 6410 Triple Quadrupole (Agilent Technologies, USA) mass spectrometer equipped with electrospray ionization (ESI) ion source in positive ion mode and MassHunter software was used for recorded and processed mass spectra of the obtained compound. The parameters of the ionization source were: gas flow $8 \mathrm{~L} / \mathrm{min}, 40$ psi, $4000 \mathrm{~V}, 300^{\circ} \mathrm{C}$, a full scan on the field $100-1500 \mathrm{amu}$ data acquisition module. Using a Jasco V650 spectrophotometer, the electronic spectra were recorded by diffuse reflectance technique in the range $200-800 \mathrm{~nm}$ with Spectralon as standard. An Analytik Jena UV-VIS Specord 210 (Germany) spectrophotometer and the software WinASPECT were used for recording the UV spectra in solution. The stock solutions were prepared in dimethyl sulfoxide (DMSO) $\left(1 \cdot 10^{-3} \mathrm{M}\right)$ and then adjusted to necessary dilutions with the same solvent. Similar molar concentrations were used to record UV spectra.

DSC 60 Shimadzu apparatus was used for Differential Scanning Calorimetry (DSC) analysis with parameters as follow: weight of the samples $3 \mathrm{mg}$, temperature increase rate of $10^{\circ} \mathrm{C} / \mathrm{min}$, and curves were recorded at the range of $40-400^{\circ} \mathrm{C}$. The melting point was determined using an Optimelt-Stanford Research System. An analyzer InoLab® ${ }^{\circledR} \mathrm{pH} /$ Cond 740 was used for determination of molar conductance for $10^{-3} \mathrm{M}$ solution of the compound (in DMSO).

\section{Obtaining method}

A solution was obtained from $1.38 \mathrm{mmol} \mathrm{STF}$ and $40 \mathrm{~mL}$ of water and has been added into a mixture of $2.76 \mathrm{mmol}$ of LVF and $40 \mathrm{~mL}$ methanol $(2: 1$ molar ratio LVF: STF) and stirred in a sealed flat-bottom flask for 8 hours, protected from light. A yellowish solution was obtained and then left overnight (at room temperature). The next day, the solvent was partially removed with a rotary 
evaporator at $40{ }^{\circ} \mathrm{C}$ under vacuum until a yellowish-white precipitate appeared into the last $10 \mathrm{~mL}$ of the mixture. The precipitate was filtrated and slowly dried in an oven set at $40^{\circ} \mathrm{C}$ for 1 hour. The compound was protected from the light and kept in a desiccator above anhydrous $\mathrm{CaCl}_{2}$.

\section{Screening of the antibacterial activity}

The obtained derivative of LVF was tested against three Gram-positive (Staphylococcus aureus ATCC 29213, Staphylococcus aureus MRSA 43300, Enterococcus faecalis ATCC 29212) and three Gram-negative (Escherichia coli ATCC 25922, Klebsiella pneumoniae ATCC 13883, Pseudomonas aeruginosa ATCC 27853) bacterial strains.

The antibacterial activity was performed by the microdilution method, according to CLSI standards. All the details of the technique were presented in our previous work $[10,11]$. The minimum inhibitory concentration (MIC) was considered in the last well without bacterial growth.

\section{RESULTS AND DISCUSSION}

Levofloxacin triflate (LVF-TF) was obtained in an attempt to synthesize a silver complex of LVF using STF as a silver salt. STF is useful in organometallic chemistry to activate the metal for metal-mediated processes and to catalyze some reactions as alcohol dehydration, vinyl hydrovinylation, electrophilic aromatic substitution, and the intramolecular hydroamination of alkyne [12, 13]. Due to the presence of the electron-withdrawing moiety $\mathrm{CF}_{3}$, the triflate is known as a weakly coordinating ligand without fluorinating properties and presents a high resistance to oxidation [14]. The results of elemental analysis and other physicochemical properties for the LVF-TF are comprised in Table 1.

Table 1. Physicochemical properties of the obtained compound $(* \mathrm{MW}=$ molecular weight, $* *$ M.p. $=$ melting point $)$.

\begin{tabular}{|c|c|c|}
\hline Physical and structural properties & \multicolumn{2}{|c|}{ Values/Results } \\
\hline Molecular formula & \multicolumn{2}{|c|}{$\mathrm{C}_{19} \mathrm{H}_{21} \mathrm{~F}_{4} \mathrm{~N}_{3} \mathrm{O}_{7} \mathrm{~S}$} \\
\hline$* \mathbf{M W}$ & \multicolumn{2}{|c|}{$511,44 \mathrm{~g} \mathrm{~mol}^{-1}$} \\
\hline **M.p. & \multicolumn{2}{|c|}{$304-309^{\circ} \mathrm{C}$} \\
\hline Appearance & \multicolumn{2}{|c|}{$\begin{array}{c}\text { a white-yellowish powder, stable to } \\
\text { air }\end{array}$} \\
\hline Solubility (at 1 mg/mL) & \multicolumn{2}{|c|}{$\begin{array}{c}\text { soluble in boiling water, } \\
\text { dimethylformamide (DMF), DMSO } \\
\text { concentrated ammonia, } 10 \% \text { sodium } \\
\text { hydroxide solution and } 10 \% \\
\text { hydrochloric acid solution }\end{array}$} \\
\hline Molar conductance $\left(\Lambda_{M}\right)$ & \multicolumn{2}{|c|}{$34 \Omega^{-1} \mathrm{~cm}^{2} \mathrm{~mol}^{-1}$} \\
\hline Elemental analysis & Found $(\%)$ & Calculated (\%) \\
\hline$\% \mathrm{C}$ & 44.77 & 44.62 \\
\hline$\% \mathrm{H}$ & 3.80 & 4.14 \\
\hline$\% \mathrm{~N}$ & 8.12 & 8.22 \\
\hline
\end{tabular}

The recorded melting point of LVF-TF was $250^{\circ} \mathrm{C}$, a value higher than that known for LVF (M.p. $225-227^{\circ} \mathrm{C}$ ), triflic acid (trifluoromethanesulfonic acid) (M.p. $34^{\circ} \mathrm{C}$ ), and lower than the one of STF (M.p. $286^{\circ} \mathrm{C}$ ) [15-17]. The molar conductance value suggests that the new compound has the characteristics of a 1:1 electrolyte $[18,19]$. No silver content was determined by FAAS.

\section{FT-IR spectra analysis.}

The most characteristic absorption bands of LVF are for stretching vibrations of the carboxyl groups $v(\mathrm{C}=\mathrm{O})$ at $1724 \mathrm{~cm}^{-1}$ and for the pyridone $v(\mathrm{C}=\mathrm{O})$ at $1621 \mathrm{~cm}^{-1}[20,21]$. The bands at $3500-2700 \mathrm{~cm}^{-1}$ correspond to the $v(\mathrm{C}-\mathrm{H})$ stretching vibrations of a methyl radical at the $\mathrm{N} 4$ nitrogen atom in the piperazinyl moiety, and (or) to the $v(\mathrm{C}-\mathrm{H})$ vibrations of methylene groups in $\mathrm{R}-$ $\mathrm{O}-$ Aryl [22]. The characteristic absorption bands of triflate anion appear in the FT-IR spectrum of LVF-TF as follows: $1262 \mathrm{~cm}^{-1}(\mathrm{~s}), v_{\text {as }}\left(\mathrm{SO}_{3}\right) ; 1227 \mathrm{~cm}^{-1}(\mathrm{~s})$, $v_{\mathrm{s}}\left(\mathrm{CF}_{3}\right) ; 1160 \mathrm{~cm}^{-1}(\mathrm{~s}), v_{\mathrm{as}}\left(\mathrm{CF}_{3}\right) ; 1036 \mathrm{~cm}^{-1}(\mathrm{vs}), v_{\mathrm{s}}\left(\mathrm{SO}_{3}\right) ; 760 \mathrm{~cm}^{-1}(\mathrm{w}), \delta_{\mathrm{s}}\left(\mathrm{CF}_{3}\right)+$ $v_{\mathrm{s}}(\mathrm{CS}) ; 637 \mathrm{~cm}^{-1}(\mathrm{~s}), \delta_{\mathrm{s}}\left(\mathrm{SO}_{3}\right) ; 572 \mathrm{~cm}^{-1}(\mathrm{w}), \delta_{\text {as }}\left(\mathrm{CF}_{3}\right) ; 517 \mathrm{~cm}^{-1}(\mathrm{w}), \delta_{\mathrm{as}}\left(\mathrm{SO}_{3}\right) ;(\mathrm{br}$, broad; $\mathrm{m}$, medium; s, strong; v, very; w, weak) [23], [24-26]. Thereby, the obtained compound LVF-TF presents differences of the FT-IR spectra comparative to LVF (Table 2, Figure 2).
Table 2. FT-IR band assignments for LVF and LVF-TF (br, broad; m, medium; s, strong; v, very; w, weak) [9], [20-23], [27-29].

\begin{tabular}{|c|c|c|c|c|c|c|c|}
\hline \multirow[b]{2}{*}{$\begin{array}{l}\text { Analyzed } \\
\text { compounds }\end{array}$} & \multicolumn{7}{|c|}{ Band assignments } \\
\hline & $\begin{array}{c}v(\mathrm{~N}-\mathrm{H}) \\
v(\mathrm{O}-\mathrm{H}) ; \mathrm{H} \mathrm{H}_{2} \mathrm{O} \\
\text { and } v(\mathrm{~N}-\mathrm{H})\end{array}$ & $\begin{array}{c}v(\mathrm{~N} \cdots \mathrm{H}) \\
\mathrm{N} 4 \text { piperazinic } \\
\text { atom and } \mathrm{v}(\mathrm{O}-\mathrm{H}) \\
\mathrm{H}_{2} \mathrm{O}, \mathrm{v}(\mathrm{C}-\mathrm{H})\end{array}$ & $\begin{array}{c}v(\mathrm{C}=\mathbf{0}) \\
(\text { carboxyl) }\end{array}$ & $\begin{array}{c}v(\mathrm{C}=\mathbf{0}) \\
(\text { carbonyl })\end{array}$ & $v_{a s}(\mathrm{COO})$ & $\mathrm{v}_{\mathrm{a}}(\mathrm{COO})$ & C-F \\
\hline LVF & $\begin{array}{c}3500-3000 \\
\text { br }\end{array}$ & $\begin{array}{l}2936 \mathrm{w} \\
2848 \mathrm{w} \\
2691 \mathrm{w}\end{array}$ & $1724 \mathrm{~m}$ & 1621 vs & $1594 \mathrm{w}$ & $1361 \mathrm{w}$ & $1160 \mathrm{~s}$ \\
\hline LVF-TF & $3046 \mathrm{w}$ & $2798 \mathrm{w}$ & - & $1712 \mathrm{~s}$ & $1622 \mathrm{~s}$ & $1422 \mathrm{~m}$ & $1160 \mathrm{~s}$ \\
\hline
\end{tabular}

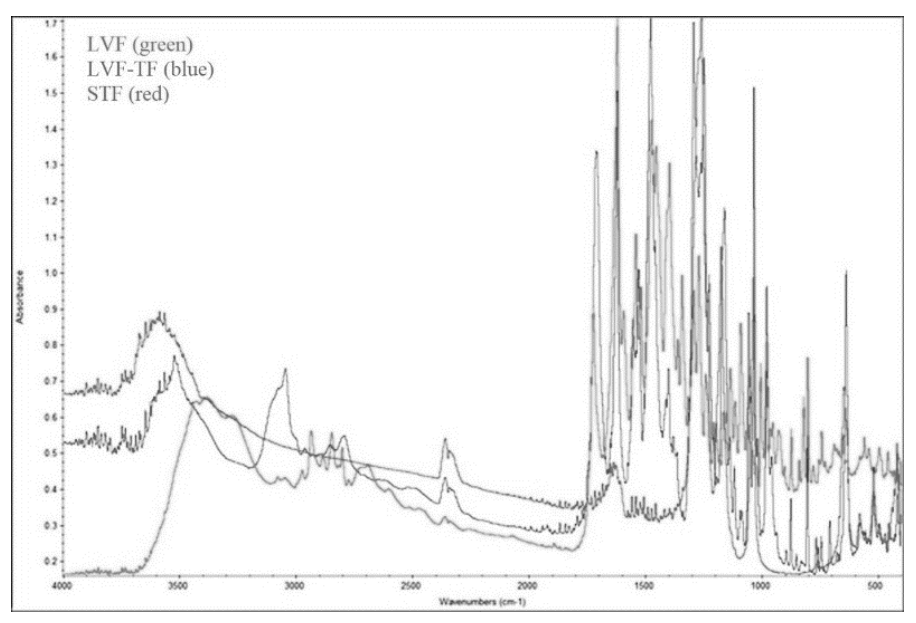

Figure 2. The overlapping FT-IR spectra of LVF, LVF-TF and STF.

\section{MS spectra analysis}

ESI-MS technique was used to determine the molecular mass of the LVF-TF, both in positive ion mode (to promote positive ion formation of LVF) and negative ion mode (to promote deprotonation of triflic acid). The known main fragmentation pattern of ofloxacin (racemic) and LVF with recorded molecular ions were previously reported [9]. As expected, the LVF presented the $362 \mathrm{~m} / \mathrm{z}$ $[\mathrm{M}+1]$ fragment and the triflate from the STF was revealed as $148.9 \mathrm{~m} / \mathrm{z}$ [M-1] (Figure 3). These data strongly suggest that the new obtained compound could be a salt, the LVF-TF.

\section{1) LVF, ESI (+)}

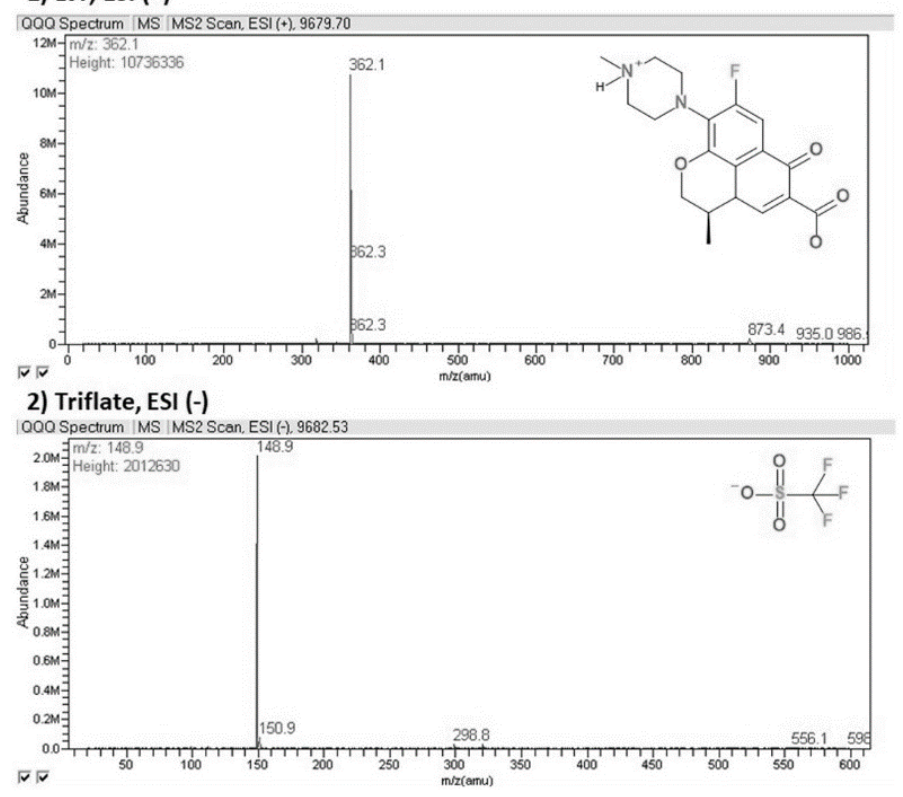

Figure 3. The recorded ESI-MS spectra of LVF-TF, 0 - $1000 \mathrm{~m} / \mathrm{z}$ (amu): 1) LVF, ESI (+), 2) Triflate, ESI (-). 


\section{UV-VIS spectroscopy}

The UV spectra of LVF and LVF-TF show some differences in terms of absorbance and absorption peaks (Figure 4). The maximum absorption peak of LVF at $304 \mathrm{~nm}$ presented a hyperchromic and a hipsochromic effect in the spectrum of the new compound. The absorption of LVF at $327 \mathrm{~nm}$ has been slightly modified in LVF-TF spectrum (Table 3). Electronic spectra recorded in solid-state of LVF-TF compared with the parent fluoroquinolone are presented in Figure 5. The LVF-TF exhibits a supplementary broad bathochromic band compared to LVF (Table 4). Thereby, the LVF-TF shows spectral differences recorded in the UV domain that can support the possibility of a new derivative.

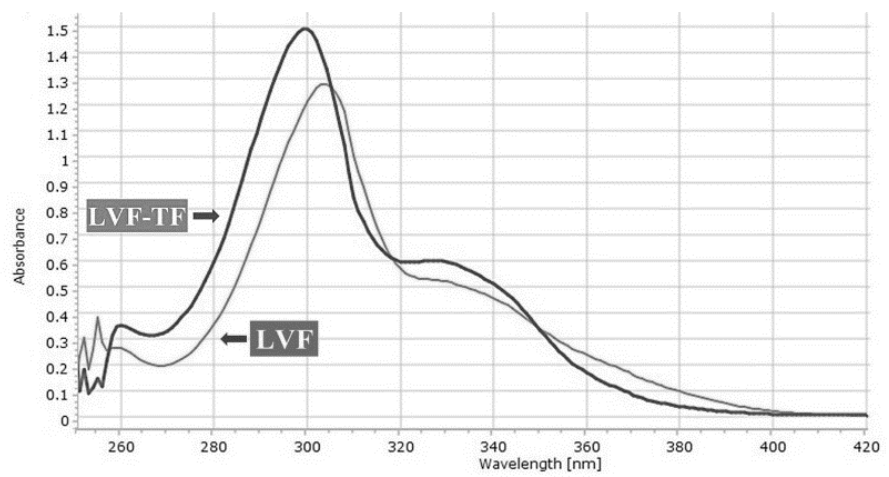

Figure 4. UV spectra of LVF-TF and LVF.

Table 3. Selective UV spectroscopic data of LVF and LVF-TF (max. = maxim).

\begin{tabular}{|c|c|c|c|c|c|c|c|}
\hline Compound & $\lambda(\mathrm{nm})$ & A & Assignments & Compound & $\lambda(\mathbf{n m})$ & A & Assignments \\
\hline \multirow[t]{4}{*}{ LVF } & 300 & 1.237 & $\mathrm{n} \rightarrow \pi^{*}$ & \multirow[t]{4}{*}{ LVF-TF } & \begin{tabular}{|c|}
300 \\
$(\max )$.
\end{tabular} & 1.492 & $\mathrm{n} \rightarrow \pi^{*}$ \\
\hline & $\begin{array}{c}304 \\
\text { (max.) }\end{array}$ & 1.280 & $\mathrm{n} \rightarrow \pi^{*}$ & & 304 & 1.305 & $\mathrm{n} \rightarrow \pi^{*}$ \\
\hline & 327 & 0.523 & & & 327 & 0.613 & \\
\hline & 370 & 0.181 & & & 370 & 0.081 & \\
\hline
\end{tabular}

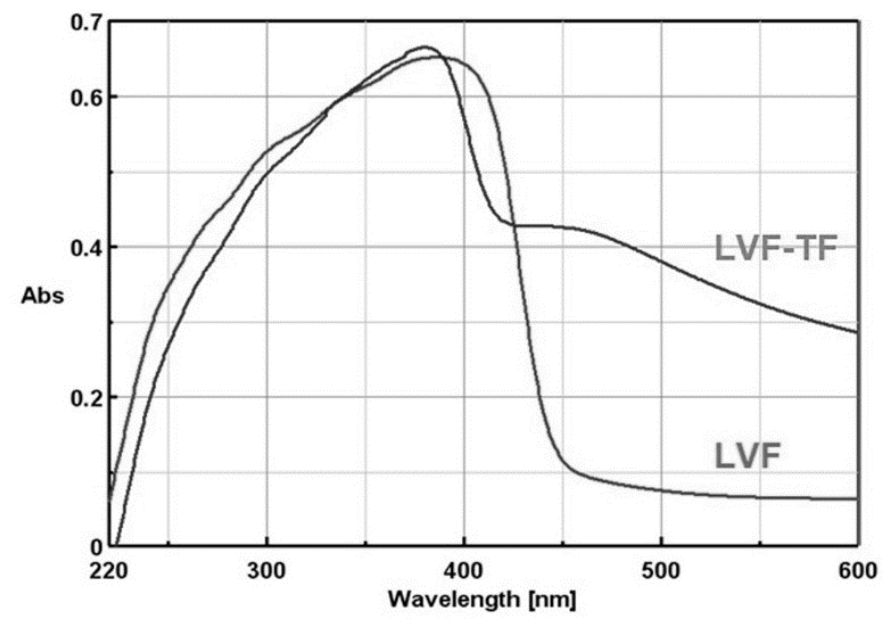

Figure 5. Electronic spectra recorded in solid-state of LVF-TF and LVF.

Table 4. Selective electronic spectra data (solid state) of LVF and LVF-TF (sh - shoulder)

\begin{tabular}{|c|c|c|c|c|c|c|c|}
\hline Compound & $\begin{array}{l}\lambda_{\max } \\
(\mathbf{n m})\end{array}$ & $\begin{array}{c}\mathbf{A} \\
\text { (a.u.) }\end{array}$ & Assignments & Compound & $\begin{array}{l}\lambda_{\max } \\
(\mathbf{n m})\end{array}$ & $\underset{\text { (a.u.) }}{\mathbf{A}}$ & Assignments \\
\hline \multirow[t]{5}{*}{ LVF } & $266 \mathrm{sh}$ & 0.417 & $\pi \rightarrow \pi^{*}$ & \multirow[t]{5}{*}{ LVF-TF } & $265 \mathrm{sh}$ & 0.350 & $\pi \rightarrow \pi^{*}$ \\
\hline & $300 \mathrm{sh}$ & 0.525 & $\mathrm{n} \rightarrow \pi^{*}$ & & $297 \mathrm{sh}$ & 0.480 & $\mathrm{n} \rightarrow \pi^{*}$ \\
\hline & $339 \mathrm{sh}$ & 0.597 & & & $334 \mathrm{sh}$ & 0.589 & \\
\hline & \multirow[t]{2}{*}{386} & \multirow[t]{2}{*}{0.65} & & & 380.5 & 0.670 & \\
\hline & & & & & 436.5 & 0.427 & \\
\hline
\end{tabular}

\section{DSC analysis}

The thermal analysis was performed using the DSC method to assess the behaviour of LVF-TF subjected to an increasing temperature comparative to LVF and STF behaviour. The melting onset and the M.p. were recorded. Also, peak temperature at complete melting and energy of melting transition (enthalpy of the transitions) were recorded. Thus, the DCS curve of LVF-TF exhibits a melting point value of $309.39^{\circ} \mathrm{C}(-6.00 \mathrm{~mW})$, higher than the recorded melting point of LVF, which corresponds to previously published values (endothermic peaks) (Figure 6) [15, 30].

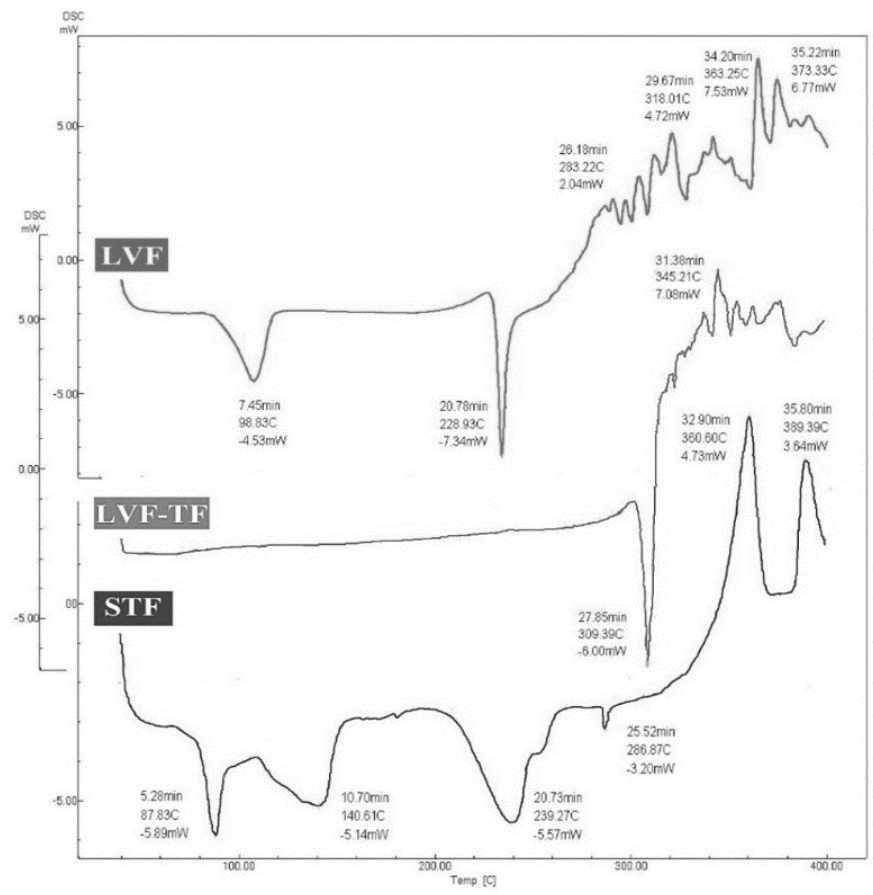

Figure 6. DSC curves of LVF-TF comparative to LVF and STF.

However, the shape of the DSC curve of STF is very characteristic, with endothermic and exothermic peaks. The endothermic peak at $239.27^{\circ} \mathrm{C}$ and exothermic peak at $360.60^{\circ} \mathrm{C}$ are similar to the peaks from the DSC curve of aluminium triflate used as a catalyst into a polymerization process [31]. These changes may be associated with sulphur trioxide group loss followed with the trifluoromethyl anion. It may be considered that the decomposition of LVF-TF started at $309.39^{\circ} \mathrm{C}$ steadily up to $400^{\circ} \mathrm{C}$.

\section{Chemical structure considerations}

Based on previously analytical results, we suggest a chemical structure for the obtained compound (Figure 7). Most likely, the obtained derivative is the triflate salt of LVF. The most persuasive arguments were brought by CHN elemental analysis, molar conductivity recorded value and the spectroscopic analysis methods (FTIR, ESI-MS and UV-VIS spectroscopy). Also, DSC analysis highlights the differences between LVF/STFs and LVF-TF derivative behaviours.<smiles>C[C@H]1COc2c3c(cc(F)c2N2CC[N+](C)(C)CC2)C(=O)C(C(=O)O)=CC31</smiles>

Figure 7. Proposed chemical structure of the LVF-TF compound. 


\section{Antibacterial activity}

LVF and LVF-TF were tested against three Gram-positive and three Gramnegative bacterial strains. MIC values are comprised in Table 5.

Table 5. The antibacterial activity data for LVF and LVF-TF on the selected bacterial strains.

\begin{tabular}{|l|l|c|c|}
\hline \multicolumn{2}{|l|}{ Bacterial strains } & \multicolumn{2}{c|}{ MIC $\left(\boldsymbol{\mu g} \cdot \mathbf{~ m l}^{-\mathbf{1}}\right)$} \\
\cline { 3 - 4 } \multicolumn{1}{|l}{ Gram-positive } & LVF & LVF-TF \\
\cline { 2 - 4 } & Staphylococcus aureus 29213 & 0.12 & 0.12 \\
\cline { 2 - 4 } & Staphylococcus aureus MRSA 43300 & 0.25 & 0.5 \\
\cline { 2 - 4 } & Enterococcus faecalis 29212 & 0.12 & 0.25 \\
\hline Gram-negative & Escherichia coli 25922 & 0.25 & 0.25 \\
\cline { 2 - 4 } & Klebsiella pneumoniae 13883 & 0.12 & 0.12 \\
\cline { 2 - 4 } & Pseudomonas aeruginosa 27853 & 0.12 & 0.25 \\
\hline
\end{tabular}

LVF-TF show similar MIC values with LVF regarding Staphylococcus aureus, Escherichia coli and Klebsiella pneumoniae. For the other bacterial species, LVF-TF did not show an increased activity compared to LVF, as we expected. However, in vivo activity of the new derivative may be different than in vitro antibacterial activity. Also, due to the deduced chemical structure, LVF-TF may present different pharmacokinetic properties comparative to LVF, features that can positively influence the antibacterial activity. Besides, more bacterial species need to be tested to find if they are susceptible to the new compound. Also, the cytotoxicity of LVF-TF will be studied.

\section{CONCLUSIONS}

Through a simple method, a new compound with molecular formula $\mathrm{C}_{19} \mathrm{H}_{21} \mathrm{~F}_{4} \mathrm{~N}_{3} \mathrm{O}_{7} \mathrm{~S}$ was obtained. The elemental, spectral and thermal analysis suggest most likely a structure of LVF salt with triflic acid. Regarding antibacterial potential, LVF-TF presented very similar MIC values to those of LVF on the selected bacterial strains. However, the compound could be further tested against other bacterial strains and the probability of a cytotoxic effect could also be studied.

\section{REFERENCES}

1. S.E. Edwards, C.M. Morel, Expert. Rev. Pharmacoecon. Outcomes Res. 19, 685, (2019).

2. D. Buckland, Prescriber. 28, 12, (2017).

3. Tuberculosis. 88, 2, (2008).

4. G.J. Noel, Clinical Medicine. Therapeutics. 1, 433, (2009).

5. A.M. Noreddin, W.F. Elkhatib, K.M. Cunnion and G.G. Zhanel, Drug. Healthc. Patient Saf. 3, 59, (2011).

6. L.S. Redgrave, S.B. Sutton, M.A. Webber, L.J. Piddock, Trends Microbiol. 22, 438, (2014).

7. G.A.R.Y. Suaifan, A.A.M. Mohammed, Bioorganic \& Medicinal Chemistry. 27, 3005, (2019).

8. H.A.A. Ezelarab, S.H. Abbas, H.A. Hassan, G.E.-D.A. Abuo-Rahma, Arch. Pharm. (Weinheim). 351, e1800141, (2018).

9. Rusu, G. Hancu, G. Tóth, S. Vancea, F. Toma, A.D. Mare, A. Man, G.M. Niţulescu, V. Uivarosi, J. Mol. Struct. 1123, 384, (2016).

10. Clinical and Laboratory Standards Institute, M100-S23 Performance Standards for Antimicrobial Susceptibility Testing Twenty-Third Informational Supplement, Wayne, PA, USA: Clinical and Laboratory Standards Institute, 2013.

11. Rusu, G. Hancu, F. Toma, A.D. Mare, A. Man, B.S. Velescu, V. Uivarosi, Farmacia. 64, 922, (2016).

12. Quillian, A.E. Fields, D. Chace, A.M. Vickery, M. Sharma, D. Zurwell, J.G. Bazemore, L. Phan, D. Thomas, C.W. Padgett, Inorg. Chim. Acta. 489, 224, (2019).

13. W.-C. Pan, M.-M. Zhang, J.-Q. Liu, X.-S. Wang, Syntesis. 51, 3101, (2019)

14. P.J. Malinowski, Z. Mazej, M. Derzsi, Z. Jagličić, J. Szydłowska, T. Gilewski, W. Grochala, CrystEngComm. 13, 6871, (2011).

15. V.L. Dorofeev, A.P. Arzamastsev, O.M. Veselova, Pharm. Chem. J. 38, 333, (2004).

16. PubChem Database, National Center for Biotechnology Information. https://pubchem.ncbi.nlm.nih.gov/compound/Trifluoromethanesulfonicacid. [Accessed 2705 2020].
17. Sigma Aldrich Catalog, Merck KgaA. https://www.sigmaaldrich.com/catalog /product/aldrich/176435?lang=en\&region=RO [Accessed 2705 2020].

18. W. Geary, Coord. Chem. Rev. 7, 81, (1971).

19. Ali, W.A. Wani, K. Saleem, Synth. React. Inorg., Met.-Org., Nano-Met. Chem. 43, 1162, (2013).

20. V.L. Dorofeev, Pharm. Chem. J. 38, 693, (2004).

21. P.C. Huber, G.P. Reis, M.C.K. Amstalden, M. Lancellotti, W. P. Almeida, Polyhedron. 57, 14, (2013).

22. H.-R. Park, T. H. Kim, K.-M. Bark, Eur. J. Med. Chem. 37, 443, (2002).

23. D. H. Johnston, D. F. Shriver, Inorganic Chemistry. 32, 1045, (1993).

24. P. Larkin. IR and Raman Spectroscopy Principles and Spectral Interpretation, Elservier, Amsterdam, 2011.

25. M. Refat, Spectrochim. Acta A Mol. Biomol. Spectrosc. 68, 1393, (2007)

26. J. Coates in Interpretation of infrared spectra, a practical approach, R.A. Meyers, ed. John Wiley\& Sons Ltd., Chichester, 2000 ; pp. 10815.

27. A.S. Sadeek, J. Mol. Struct. 753, 1 (2005).

28. Sousa, V. Claro, J.L. Pereira, A.L. Amaral, L. Cunha-Silva, B.d. Castro, M.J. Feio, E. Pereira, P. Gameiro, J. Inorg. Biochem. 110, 64, (2012).

29. K. Nakamuto, Infrared and Raman Spectra of Inorganic and Coordination Compounds, Part B: Applications in Coordination, Organometallic, and Bioinorganic Chemistry, Wiley, Hoboken, 2009.

30. M.J. O'Neil in An Encyclopedia of Chemicals, Drugs, and Biologicals, M.J. O’Neil, P.E. Heckelman, C.B. Koch, K.J. Roman eds. John Wiley \& Sons, Hoboken, 2006 ; pp. 1171.

31. E.D. Márquez, E.V. Santiago, S.H. López, Physical Chemistry. 9, 1, (2019). 